\title{
Assessing Determinants of Population Fertility in Hosanna Town, South Ethiopia
}

\author{
Zelalem Yekoye Alemayehu \\ Department of Geography and Environmental Studies, Wachemo University, Hossana, Ethiopia
}

\section{Email address:}

yekoyezelalem@gmail.com

\section{To cite this article:}

Zelalem Yekoye Alemayehu. Assessing Determinants of Population Fertility in Hosanna Town, South Ethiopia. Journal of Health and Environmental Research. Vol. 3, No. 2, 2017, pp. 22-26. doi: 10.11648/j.jher.20170302.11

Received: January 21, 2017; Accepted: February 3, 2017; Published: March 11, 2017

\begin{abstract}
Ethiopia is one of the developing country in which high rate of population growth is observed due to the strong impact of socio-economic and demographic factors. This study is a community based and cross sectional study focused on assessing determinant factors of population fertility in Hosanna town, particularly on women who are found in the age bracket 15-49. Data were collected using pre tested structured \& unstructured questionnaire, focused group discussion from 200 systematically selected samples and through assessing relevant documents of different type. A total of 209 women within the group 15-49 were drawn as a sample and only 200 women were taken in this study since the others did not return the questionnaire given to them during interview time. After data organization, thoroughly analysis was made using statistical techniques such as correlation and found that, sex preference has positive relationship. On the other hand age at first marriage, educational level, birth space and income level of women and birth space between two consecutive children were negatively associated. In the meantime occupational type and religion of a woman is found to be a dependable factor. And this still shows that there is very high fertility level in the study area compare to the national and the regional MEBC due to the profound impact of the above demographic and socio-economic impacts on women. Therefore on this study, the concerned government institutions, NGOs and private organization should encourage women who are found in the age group 15-49 to involve in education up to higher level, to have their own permanent means of income generation, not to get into marriage at their early age, to feed breast for optimum time and to have an average time gap between two consecutive children. Religious leader should also make women feel free to use contraceptive methods to have well-sized family members.
\end{abstract}

Keywords: Fertility (having a child), Demographic and Socio-Economic Factors, Women (15-49 Ages)

\section{Background of the Study}

In the early stages of development, the hunters, gatherers and farmers, used only simple tools and moved from place to place. Even after the agricultural revolution about 12,000 to 8,000 years ago, the size of human population was small and human activities were simple in nature. As such, human impact on environment was insignificant.

The population growth was slow which may be ascertained from the fact that the world population in the first century AD was only 250 million. The stage for rapid population growth was set by the expanding trade in the sixteenth and the seventeenth centuries. The world population at the dawn of Industrial Revolution i.e. around 1750 was about 0.5 billion. It, however, exploded in the eighteenth century after the Industrial Revolution. A series of dramatic technological changes rapidly expanded the resource base and provided a foundation for accelerated population growth that continued for more than two centuries [10].

However, population growth beyond a certain level may compound the problems in a developing economy. Growing populations are putting greater pressure on land and natural resources.

Commonly, the rate of population growth in different parts of the world is compared to get a world pattern. For instance in Africa annual population growth ( 2.4 percent) is the highest among the major world regions. In Nigeria, which is Africa's most populous country, the annual rate of population growth is 2.4 per cent. At this rate, Nigeria's population 
(about 123 millions) will double in less than 25 years. Ethiopia is the 2nd most populous country in Sub-Saharan Africa with estimated total population size of 62.5 million in July 2000 and a growth rate of $2.73 \%$ b/n 2000- 05 [9]. Recently, this number increased around 73.2 million in 1990s [4].

There is an also regional difference in term of fertility within the country which depends on several conditions. $\mathrm{SNNP}^{1}$ \& Tigray (5.7 children per woman) have highest total fertility rate followed by Amhara and Oromia, which have a TFR of 5.4 children per woman each [4]. The Overall fertility level for the country at this time [9] is 5.2 per woman. At the same time, SNNP (Wenago district had 864 sq. km) is one of densely populated region in the country. Hence, in SNNP region, Hosanna is one of the places where fast population growth is observed in Ethiopia [4].

Growth rate of Hosanna town population is $6.1 \%$ [2]. On the other hand, the growth rate of urban population of the region is $2.9 \%$ [4]. This is mainly triggered by the occurrence of high fertility. Large proportion of the town's population belongs to below 15 years old $(31.5 \%)$. This indicates that fertility rate in the town is high [2].

And also there is a limited research work in this regard/issue/. Therefore; this study tries to assess that factor that deters fertility in Hosanna town. This will be important to that of the local official in particularly and for policy maker at large to curve population growth by promoting those deterring factors since the country is implementing anti population policy.

\section{Materials and Methods}

\subsection{Description of the Study Area}

Hosanna town administration is the capital of Hadiya zone as well as Limo woreda. It is one of the 22 reform towns of southern region. It is one of the four big towns of the region which have second grade status (like Dilla, Woliyta, Sodo and Hossana). As far as the structural arrangement of the town, it is divided in to 3 sub cities, 8 kebeles \& 160 localities. According to Central Statistical Agency [4] report, the total area of the town is $100 \mathrm{~km} 2(10,200$ hectares) [2].

Regarding to location, the astronomical location of the town is found in geographic coordinate between $07^{\circ} 33^{\prime} \mathrm{N}$ latitude and $35^{\circ} 52^{\prime} \mathrm{E}$ longitudes respectively. In its relative location Hossana town is bounded in four peasant associations.

The terrain character of the study area is mainly consists of different size plain gorge, hills and steep slope. Many of the terrains fall under highland groups. Rocks such as ignimbrite, rhyolities, pumice and volcanic and deposit commonly prevail over the study area. The town and its environs are found within the rift valley which is tectonically unstable because they are places of recent volcanic as well as seismic activities. Therefore it experiences a concurrent earth quack $[2]$.

${ }^{1}$ SNNP-Sothern Nation Nationality \& peoples
According to the traditional climate zone classification, as a result of the effect of altitude, the climatic condition of Hossana is classified under Woina Dega.

The altitude of the study area ranges from 776meters to 2220 meters above sea level. This range of altitude enables the study area to have different amount of temperature and rainfall through of the year. According to the National metrological service agency, the mean annual temperature and mean annual rainfall is estimated to be $16.9^{\circ} \mathrm{C}$ and 1071 $\mathrm{mm}$ respectively. The hottest month of the town is March. On the other hand July is the coldest month. This town receives an average of $1500-1800 \mathrm{~mm}$ rainfall annually [2].

The dominant types of economic activities that are practiced by the people include commerce, urban agriculture and civil servant.

\subsection{Sampling Techniques}

The sampling techniques employed in this study were multi stage and simple random sampling techniques. Based on the total population of women who are found in between of 15-49 age group (19296), the total number of residential sub cities (3) and kebeles (8) of the study area the most appropriate techniques were employed. In the selection of the desired sample units from the different sub cities and the kebeles, the researcher applied the following steps. The first step was the selection of the desired number of kebeles from the sub cities in the study area, in this case among the eight (8) residential kebeles of which three were selected from each sub cities. Namely Arada, Lichanba, and Bobicho were selected. The reason behind the selection of only three kebeles from the three sub cities is only for the sake of management and administration of the task. The next step was selection of sample of woman, which was obtained proportionally to each kebele population size. Hence, a total of 209 women were taken as a subject of this study.

\subsection{Methods of Data Analysis}

In order to achieve the specified objectives and to answer the given research questions, the study analyzed, summarized, and presented the data both qualitatively and quantitatively. The qualitative method was employed to analyze the views of women and validate the quantitative data obtained through questionnaires. Specifically, the quantitative data were analyzed, summarized, and presented in the form of frequency table and percentage by using appropriate descriptive statistics like mean value.

\section{Result and Discussion Analysis of Data on Factors that Determine Fertility Level of Respondents}

In this section analysis and interpretation of data was made to investigate the effect of Demographic, Socio-economic and cultural determinants of population fertility.

A. Demographic factors Age versus fertility 
Age at first marriage has a great effect on the total birth rate of the society as it determines the proportion of the population in their reproductive age. This is true especially in most developing countries including Ethiopia. The highest percentages of the respondents $(42.5 \%)$ in this study are found in the age group 15-19 with their 4.34 MCEB. This is because half of the respondents are found married below and around the national average time (18 years) and this exposed them to have more children in their reproductive age.

\section{B. Socio-Economic Factors versus Fertility}

[1] and others have indicated that women in traditional societies want to have large family for several reasons. On the other hand, in societies where women have high SocioEconomic status (better educational and employment opportunities) they tend to aspire for smaller family size (limit) their fertility [6].

Education versus fertility

Education is believed to be one of the factors that influence fertility. It tends to influence fertility by increasing the age at first marriage and by changing the attitude of a person to rationalize the family size [3]. Its effect on fertility has been marked as with uneducated mothers having twice as many children as women with at least some secondary education [5].

According to this study, fertility is negatively associated with level of education. That is high fertility is observed for illiterate women followed by women with only non-formal education (read and write). This is because educated women have better knowledge of family planning than non-educated women. Therefore investigation made in the study area go in line with studies made by other's which are already indicted in the literature like [8].

\section{Type of occupation versus fertility}

Increasing in the participation of women in the labor force has been strongly advocated for reducing fertility and promoting development [7].

It is considered to be one of the socio economic factors that affect fertility in the study area. Some types of women occupation is directly related to child bearing and earning like house wife while others like office work would face shortage of time in bringing up children. Respondents were categorized in to three groups according to their occupational status as of government employed, housewife and selfemployed.

Table 1. Distribution of respondents by their occupational status and mean of ever born children.

\begin{tabular}{lllll}
\hline $\begin{array}{l}\text { Occupational } \\
\text { Status }\end{array}$ & $\begin{array}{l}\text { No of } \\
\text { respondents }\end{array}$ & Percent & $\begin{array}{l}\text { No of children } \\
\text { ever born }\end{array}$ & MECB \\
\hline $\begin{array}{l}\text { Housewife } \\
\text { Government }\end{array}$ & 86 & 57 & 387 & 4.50 \\
$\begin{array}{l}\text { Employed } \\
\text { Self Employed }\end{array}$ & 53 & 21 & 180 & 3.39 \\
Total & 61 & 22 & 235 & 3.85 \\
\hline
\end{tabular}

Source: Field survey, 2015

The highest average number of observed in house wife women which is 4.5 whereas self-employed women had an average number of children (3.85) and the remaining group that is government employed had the lowest mean number of children (3.39) compared to others. The smaller number of children in government employers could be explained to the better attainment of education, better utilization of contraceptive device and better access to other facilities than others.

\section{Family Income versus Fertility}

Improved income implies an improved nutrition, health condition and educational opportunities. Improved income also means leading to low infant mortality and once a particular family is convinced that increased survival rates. Fertility will decline because fewer births are required to limit desires family size. This is also true in this study. As the average monthly level of income for each respondent increases from one thousand or equal to thousand to four thousand or above their mean child ever born becomes lower from 4.28 to 4.01 .

\section{A. Religion versus Fertility}

Religion has a strong impact on fertility like other socio economic factors. Reproductions norms vary among various religion group encourage prolonged breast feeding and sexual abstinence after birth or during certain months of year. In some others cultural practices encourage and support early marriage and prevent the use of contraception because of the religion doctrine as mentioned in many literatures.

Table 2. Distribution of respondents by their religion affiliation and mean of ever born children.

\begin{tabular}{lllll}
\hline Religion & $\begin{array}{l}\text { No of } \\
\text { Respondents }\end{array}$ & Percent & $\begin{array}{l}\text { No of ever born } \\
\text { children }\end{array}$ & MECB \\
\hline Orthodox & 62 & 31 & 272 & 4.38 \\
Protestant & 106 & 53 & 415 & 3.91 \\
Muslim & 13 & 6.5 & 47 & 3.61 \\
Catholic & 19 & 9.5 & 68 & 3.57 \\
Total & 200 & 100 & 802 & 4.01 \\
\hline
\end{tabular}

Source: Field survey, 2015

As the above table depicts fertility among the followers of orthodox is the highest with a mean parity of 4.38. It is followed by Muslim and catholic which account for 3.91 and 3.61 respectively. The remaining group, protestant Christian religion follower, accounts for 3.57. There is a slightly difference between orthodox and protested Christianity as well as between Muslim and catholic religion followers.

\section{B. Other Non-socio-Economic Factors}

The inter relationship between birth Spacing and fertility

The average time interval between two consecutive births can be taken as the other factor, which affects the fertility of the women.

According to this survey, the dominant birth interval between two consecutive births is from $2-2 \frac{1}{2}$ years. This is to mean that about 38 percent of the respondents in Hosanna town give birth from 2-21/2 year's gap and the average number of children per women in this group is 4.06 . The second dominant birth interval is two and half years is followed by one or less year gap. This means that 27 percent of the respondents give birth in every one or less year gap. 


\section{Sex preference}

Sex preference is one of the factor that affects the level of fertility in a certain family particularly and in national level at large. Respondents were asked regarding own their intension about sex preferences. And most of them were responded as selective of sex of a child.

Table 3. Distribution of respondents by their sex preference and average number of ever born children.

\begin{tabular}{lllll}
\hline Sex type & $\begin{array}{l}\text { No of } \\
\text { respondents }\end{array}$ & Percent & $\begin{array}{l}\text { No of children } \\
\text { ever born }\end{array}$ & MCEB \\
\hline Male & 33 & 16.5 & 147 & 4.45 \\
Female & 47 & 23.5 & 210 & 4.46 \\
Both & 120 & 60.0 & 445 & 3.70 \\
Total & 200 & 100 & 802 & 4.01 \\
\hline
\end{tabular}

Source: Field survey, 2015

As the above table shown, the largest portions of the respondents were found under the category of both sexes which account for about 60 percent. Respondents under female shared 47 percent followed by respondents who found under male which constitute 33 percent. Based on the data those respondents who got only male or female child had high MCEB (4.45 and 4.46) where as those respondents who got both male and female child had relatively low MCEB (3.70). This indicates that those families who had only male or female child were engaged in having additional child until they get the desired type of child's sex. This in turn causes to have large number of children and family size.

\section{Conclusion}

The study has shown already a direct relationship between the determinants of fertility (demographic, socio- economic and cultural variables) fertility. Hence the analysis shows that the age at which female get in to marriage have reducing effect on fertility performance of woman.

It also shows that women married at age less than fifth teen years have the highest average number of children and those at thirty (30) and above years have the lowest number of children. Thus it is possible to conclude that all other thing remain constant fertility rate decrease with increasing age at first marriage.

Concerning on the socio-economic and cultural variables such as education attainment is negatively related with fertility performance. Thus illiterate women were found to have highest mean parity where as women educated up to secondary and above experiencing the lowest near parity.

Similarity, disparity of fertility has observed among different occupational status. More respondents were found to be house wife with highest mean number of children whereas self-employee women had relatively medium mean parity of children women who were literate and currently employed have better social status related to low fertility.

There is a variation level among the different religion groups based on the degree of variation in attitude towards early or late marriage and contraceptive use. Muslim and protestant respondents have high fertility experiences whereas orthodox respondents and catholic respondents have relatively low fertility.

Based on the findings knowledge and use of contraceptive method is influenced by different factors. Among these, educational attainment is positively associated with the level of practice of contraceptive method.

\section{Recommendation}

In general, fertility is very high in the study area (town) even though it has been declining from time to time as like as most part of the country due to continues attitudinal changes of the women through informal and formal education. However, it has also varied according to the socio-economic status, cultural and demographic character of the women. Therefore in order to reduce the level of fertility and to increase the awareness level of the women in the study area the writer recommended the following remedies.

- Females should be encouraged to participate in education to increase awareness level about family planning, contraceptive use and their socio- economic status.

- Parents should encourage sending their children to school, especially female children for that it delays the age at first marriage and increasing the socio economic status of women.

- The social and economic consequence of high fertility at the individual, family and community levels should be addressed and strategies should be properly and strictly implemented by local government officials to bring small family size.

- There must be a task of convening those dogmatic religion leaders who prevent the use of contraceptive method as immoral to be moral right.

- There must be a socio- economic program that allows the high and free enrolment of women to increase their average monthly income and raise their ability of decision making in their family issues.

The low level of awareness of family planning and extremely low level of practice suggests the need of expanding and strengthening intervention program to raise awareness and uses of it.

\section{References}

[1] Boserup. (1985). EConomic and Demographic Interrelations in sub-Saharan Africa. population and development Review $V$. II No (3), 383-399.

[2] Council, H. T. (2011). Unpublished Document. Hossana Ethiopia: Hossona Town City Adminstrative.

[3] CSA. (1993). The 1990 National Family and Fertility Survey Report. Addis Ababa, Ethiopia: CSA.

[4] CSA. (2007). Population and housing census of Ethiopia. Addis Ababa: CSA. 
[5] EDHS (2013). Component of fertility changing in Ethiopia. Addis Ababa.

[6] Hogan, D. e. (1999). Household organization, women's Autonomy and Contraceptive Behavior in Southern Ethiopia. Studies in FP. Vol 30. No. 4. Addis Ababa.

[7] Mersie et al. (1990). population and Development Bulliten Vol I No II. Addis Ababa.
[8] S. Degraff (1988). Fertility to theory, Emperical Research and policy Issue. Geneva: IOL.

[9] USAID (2005). DHS Working Papers: Differentials of Early Teenage Pregnancy in Ethiopia, 2000, and 2005, Calverton, Maryland, USA.

[10] UN (2015). World population projection to reach 9.7 billion by 2050 , Department of Economic \& social Affair, UN. 